\title{
Këshillimi Motivacional në Fushën e Shëndetësisë
}

\author{
Msc. Lejda Abazi \\ University of Vlora \\ Faculty of Human Sciences
}

\section{Doi:10.5901/jesr.2014.v4n2p332}

\begin{abstract}
Abstrakt
Per të vendosur një komunikim të mirë është e nevojshme para së gjithash të vëzhgosh cilin person ke përpara, në të gjithë globalitetin e tij, duke patur parasysh rëndsinë që problemi i shëndetit përbën për personin. Përmirësimi $i$ komunikimit me personin e semur do të thotë të njohësh aspekte të ndryshme të personalitetit te tij ku operatori sanitar i përgjigjet me modalitete interaktive që konsiderojne nevojat e ndryshme dhe përgjigjet emocionale verbale dhe joverbale. Është e rëndësishme të mësosh të komunikosh në mënyrë efikase duke e dëgjuar pacientin ndërsa na rrefen çrregullimin, patologjinë dhe efektet qe kjo ka në jeten e perditshme, në familje, në pune e në raporte sociale, sepse ajo çfarë na tregon pacienti nuk është vetëm semundja, por vetë jeta e tij. Intervista e motivimit është një tip këshillimi që nis nga këshillimi i raporteve. Këshillimi i motivuar qëndron konform kritereve si: përballimi, ndryshimi, autonomia. Në fushën e shëndetësisë intervista motivuese është e dobishme për: a) pacientin, b) operatorin sanitar, c) sistemin shëndetësor në përgjithësi. Këshillimi motivues është një lloj këshillimi plus diçka tjetër si: (aleancë terapeutike mjek-pacient, anamneza, stade të ndryshimit në të cilin gjendet pacienti, objektivat e tij, objektivat e operatorit sanitar, shkalla e motivimit, kontrata mbi objektivat). Tre pikat kyçe të këshillimit motivues janë: 1. aleancë terapeutike 2. qëndrim empatik 3. negocim i objektivave të synuara. Në asistimin e pacientëve me sëmundje kryesisht terminale por jo vetëm, komunikimi paraqet një moment strategjik kure, një element kualifikues të shërbimit të ofruar dhe një pritshmëri legjitime e pacientit dhe familjes. Komunikimi midis ekipit mjek-infermier dhe pacientit, është një faktor kryesor i një asistimi cilësor dhe lidhet direkt me rezultatet e mira klinike. Perballimi i patologjive nënkupton të bërit parandalim duke gjeneruar në popullat aftesinë për të konsideruar drejt sëmundjen dhe të kuruarit me terapitë e duhura të cilat nuk janë vetëm farmakologjike. Po aq të rëndësishme janë dhe marrëdhëniet, raportet e ndihmës me të sëmurin dhe familjarët e tij. Aftësia e raportimit dhe komunikimit në mënyre efikase përfaqëson një nga aftesitë më të mëdha të kërkuara sot operatorëve që punojnë në fushën e infeksioneve nga HIVIAIDS apo sëmundjeve onkologjike terminale dhe konsiston në aftesi komplekse që implikon njohuri profesionale dhe faktor personal.
\end{abstract}

Fjalëkyc: komunikim, këshillim motivacional, pacient, operator sanitar.

\section{Hyrja}

"Mjeku sheh sëmundjen, pacienti ndjen dhimbjen, janë dy gjëra krejt të ndryshme, Umberto Galimberti". Konsultimet e literaturave, udhëzuesve, teksteve mbi tematika si Duahnpirja, Alkoli, Komunikimi me pacientët Hiv/Aids, i kushtojnë rëndësi dhe hapësirë intervistës motivuese si një nga format e para të ndërhyrjes drejt promovimit dhe parandalimit nga operatorët e sistemit sanitar. Intervista e motivimit është një nga stilet e counseling më efikase për subjektet që paraqesin probleme vartësie. Ajo përkufizohet nga vetë krijuesit e saj si "një ndërhyrje e orientuar, e përqëndruar tek klienti-pacient, ku ky i fundit gjendet i përfshirë në përballimin dhe zgjidhjen e konfliktit mbi ndryshimin e sjelljes se tij" (Miller, Rollnick, 1991). Intervista motivuese lind në Norvegji me 1983, si vepër e një psikologu të ri amerikan, William Miller dhe nga punimi i tij kemi sot deri në vitin 2012, më tepër se 1000 publikime që trajtojnë intervistën e motivimit. Zhvillimi i mëvonshëm i intervistës motivuese dhe përhapja e saj lidhen me publikimin e manualit Miller dhe Rollnick $(1991,2002)$ dhe përkthimit të tij në dhjetra gjuhë. Publikime të metëjshme për aplikimin e intervistës motivuese i gjejmë në fushën e shëndetësisë (Rollnick dhe kolegët 1999, 2008), në drejtësinë penale (Walters dhe kolegët 2007), me pacientët psikiatrik (Arkowitz 2008), me adoleshentët dhe të rinjtë (Naar - King, Suarez 2011) dhe shërbimi social (Hohman, 2011).

Qëllimi i këtij studimi është prezantimi dhe njohja me intervistën motivuese (karakteristikat, parimet themelore, aspektet metodologjike, fushat e aplikimit, rëndësia e saj). Eksperienca ka treguar mungesën ne efikasitetin të screening të bazuar në friksimin, ndëshkimin si mesazhi i shkruajtur në paketën e cigareve. Duhet synuar në mirëqenien e përgjithshme, të ndërgjegjësohemi për të bërë diçka për veten tonë dhe pa vuajtur nga asnjë sëmundje. Autonomia, përgjegjshmëria personale e pacientit duhet të drejtojë operatorin, pasi nuk ka kuptim realizimi i ndërhyrjes me forcë 
duke u ndjerë i gjithëpushtetshëm. Një mendje e angazhuar për t'u mbrojtur, nuk është e disponueshme për hyrjen e asnjë informacioni, as në pranimin e ndryshimit.

\section{Metodologjia}

Tema e studimit të zgjedhur është kryesisht teorik duke u bazuar në grumbullimin, përzgjedhjen dhe revizionin e literaturës, dokumentave, në përshkrimin e materialit të grumbulluar me metodë historike, krahasuese.

\section{Rezultatet dhe Diskutimet}

Intervista e motivimit është një metodë komunikimi më tepër sesa një seri teknikash apo strategji specifike. Objektivi i saj është të drejtojë pacientin drejt motivimit për ndryshim, duke nxitur arsyet e ndryshimit te vetë pacientit. Me në qendër pacientin, intervista motivuese nxjerr në pah faktin se ndryshimi i sjelljes është vullnetar dhe përgjegjësia ndaj vendimeve dhe rezultateve i takojnë pacientit. Kjo metodë është direktive, adresuar zgjidhjes së ambivalencës. Miller dhe Rollnick (2002) sugjerojnë tre proçese përmes së cilave intervista e motivimit arrin në rezultatet e synuara perkatesisht: bashkëpunimi, përjetimi, autonomia. Një marrëdhënie bashkëpunuese midis mjekut dhe pacientit është elementi kyç i intervistës së motivimit. Mjeku duhet të komunikojë vullnetin për një marrëdhënie miqësore, duke ofruar më tepër mbështetje sesa bindje apo detyrim. Nga vëzhgimi në kontekstet ambulatoriale, spitalore, mbizotron komunikimi mjekpacient ku ky i fundit i trembur mohon diagnozën si shenjë refuzimi. Shpesh mungon dëgjimi, mirëpritja e pacientit, gjuha e duhur, informimi mbi diagnozën. Mjeku i frustruar, zhvillon një bisedë kërcënuese, friksuese, si një figurë prindërore. Intervistë e tillë nuk frymëzon marrëdhënie besimi, shprese, që të motivojë ndryshimin e stilit të jetesës së pacientit, si bashkëjetesa me sëmundjen, gjërat që do ndryshojnë, komunikimi i avantazheve dhe disavantazheve të semundjes, gjetja e kompensimeve, prodhimi i empowerment të pacientit, identifikimi i pikave të forta dhe resurseve të pacientit.

\subsection{Bazat Teorike të Intervistës Motivacionale}

William Miller i njohur si ekspert në trajtimin e alkoolizmit, kryente supervizione në punën e psikologëve të rinj norvegjez, të cilët ishin të impresionuar nga mënyra se si ai trajtonte pacientët duke i kërkuar të shkruante "metodën e tij". Shkruante Miller në punimin e tij: "...të gjitha dështimet terapeutike $i$ atribohen pacientit, mohimit, rezistencës, mungesës së tij të motivimit... në të kundërt, të gjitha sukseset $i$ atribohen karakteristikave të programit apo cilësis së operatorit një sistem atributesh tepër komod për operatorin": nëse gjërat shkojnë mirë, merita është e operatorit, nëse shkojnë keq faji është i pacientit. Përkundrejt ketij parimi të përshkruar në mënyrë "mizore", Bill Miller në punimin e tij kreu një operacion kopernikan: vendosi në qendër pacientin dhe i ktheu operatorit rolin që i takon, atë të asistimit, favorizimit dhe të udhëheqesit, ndryshe nga ai i të qenit zot që nxit ndryshimin përmes proçesit ku ky i fundit është eksperti dhe tjetri një subjekt pasiv. Ky është thelbi i intervistës motivuese, forca, efikasiteti i saj; por vetëm se këtij parimi teorik iu shtuan një metodë praktike koerente dhe e riprodhueshme, duke u bërë e matshme dhe me mundesi aplikimi në fusha të ndryshme sociale dhe shëndetësore.

Bazat themelore të intervistës së motivimit fillimisht identifikohen në tre teoritë eksistuese në psikologji: 1) Disonanca konjitive e Festinger (1957); 2) Vetëperceptimi i Bem (1967) dhe 3) Terapia me në qendër klientin e Carl Rogers $(1951,1970)$.

1. Teoria e Disonancës konjitive e Festinger - është marrë në formën origjinale të përshkruar nga (Miller dhe Rollnick 1991, 1994) si discrepancy, që nënkupton perceptimin inkoerent të gjendjes në të cilën personi ndodhet, dhe asaj që mendon mund/duhet/dëshiron të jetë.

2. Teoria e vetëperceptimit të Bem - pohon se në situatat kur personat janë të pavendosur mbi një sjellje, janë të prirur t'u besojnë pozicioneve favorizuese që argumentojnë.

3. Teoria me në qendër klientin të Carl Rogers - sipas tij, "një pranim i plotë dhe i pakushtëzuar" është në vetëvete një proçes terapeutik. Empatia e Rogers ("mirëkuptimi, përkushtimi jo posesiv, mungesë gjykimi") realizohet përmes proçesit relacional të dëgjimit refleksiv. Dëgjimi refleksiv që nuk është thjesh kthim, por shtim i kuptimeve, gjithashtu instrument për të shmangur bllokimet dhe kurthet në komunikim. Transformimi i dëshiruar arrihet përmes përdorimit të teknikave që kanë parasysh vizionin e botës së pacientit, në një atmosferë empatie, mikpritje dhe besimi.

Teknikë e tillë lind si rezultat i tre kushteve kryesore:

1. studimet mbi përbërësit efikas të ndërhyrjes së shkurtër 
2. modeli i ri i proçesit të ndryshimit i përpunuar nga Prochaska dhe DiClemente

3. vizioni mbi ambivalencën e pacientit si sintom i konfliktit trajtim-shmangie

\subsubsection{Përbërësit Efikas të Ndërhyrjes së Shkurtër}

Përkufizohet si ndërhyrje e shkurtër një ndërhyrje që realizohet në 4 intervista me kohëzgjatje të ndryshueshme nga pak minuta në një orë. Objektivat e ndërhyrjes së shkurtër janë:

1. motivimi i pacientit për t'u nënshtruar trajtimeve me kohëzgjatje më të madhe

2. moderimi i konsumit

3. realizimi i ndërprerjes, shkëputjes

"Përbërësit aktiv" të ndërhyrjes së shkurtër sipas autorëve (Miller, Sanches) janë:

- Feedback

- Përgjegjshmëri

- Këshilla (Advertising)

- $\quad$ Lista e alternativave (menu of topics)

- Empatia

- Vetëefikasiteti (Self-efficacy)

\subsubsection{Ndryshimi Sipas Modelit Prochaska dhe Di Clemente}

Në modelin e Prochaska dhe Di Clemente tre janë aspektet thelbësore që duhen konsideruar:

1. fazat e ndryshimit

2. proçeset e aktivizuara

3. nivelet e perfshira në vetë ndryshimin

Fazat që vijojnë përgjatë proçesit të ndryshimit janë:

- Precontemplation: e karakterizuar nga munges ndërgjegjshmërie të nevojës për ndryshim

- Contemplation: e karakterizuar nga shfaqja e sjelljeve ambivalente drejt vartësisë, që e bëjnë subjektin të aftë për të analizuar anët pro dhe kundër të sjelljes së tij, por jo për të vendosur ne favor të ndryshimit.

- Determination: shfaqja e dëshirës per të bërë diçka, por që nuk konkretizohet me plane veprimesh të caktuara.

- Action: veprimi drejt realizimit të planeve që synojnë ndryshim.

- Maintenance: ku subjekti kërkon të ruajë të fiksuara rezultatet e arritura.

- Relapse: rikthimi në gjendjen fillestare.

\subsubsection{Proçeset e Ndryshimit}

Proçeset e ndryshimit mund të përkufizohen si "tipe aktivitetesh të ndërmarra ose të jetuara nga personi kur ndryshon mënyrë të menduari, të sjellurit përballë një problemi të caktuar" (Spiller, Scaglia, Ceva).

\begin{tabular}{|c|c|}
\hline Stadi i klientit & Detyrat e operatorit për të nxitur motivimin \\
\hline Precontemplation & $\begin{array}{l}\text { a. lë të kuptohet dyshimi } \\
\text { b. të risë tek klienti perceptimin e rrezikut dhe të problemeve } \\
\text { që sjellja aktuale krijon. }\end{array}$ \\
\hline Contemplation & $\begin{array}{l}\text { a.përcaktimi } \mathrm{i} \text { anëve pro dhe kundër të sjelljes aktuale } \\
\text { b.përcaktimi } \mathrm{i} \text { arsyeve për të ndryshuar dhe rreziqet që hasen } \\
\text { nëse nuk ndryshohet. } \\
\text { c. nitja e vetëvlerësimit tẽ klientit për tẽ ndryshuar sjelljen } \\
\text { aktuale }\end{array}$ \\
\hline Determination & $\begin{array}{l}\text { a. të ndihmojë klientin për të përcaktuar mugën më të mirë për } \\
\text { të gjetur mënyrën e ndryshimit. }\end{array}$ \\
\hline Action & $\begin{array}{l}\text { a. të ndihmojë klientin të përshkojë hapat e nevojshme për } \\
\text { aktivizimin e ndryshimit. }\end{array}$ \\
\hline Maintenance & $\begin{array}{l}\text { a. të ndihmojë klientin për të identifikuar dhe përdorur } \\
\text { strategjitë të cilat pengojnë një rikthim të sjelljes së } \\
\text { mëparshme. }\end{array}$ \\
\hline Relapse & $\begin{array}{l}\text { a. të ndihmojë klientin për të riaktivizuar proçeset e } \\
\text { contemplation, determination, dhe action pa u demoralizuar } \\
\text { mbi rikthimin e gjendjes fillestare. }\end{array}$ \\
\hline & 334 \\
\hline
\end{tabular}


Trajtuar nga Miller dhe Rollnick (1994), Intervista e motivimit, teknika të këshillimit për problemet e alkolit dhe të vartësive të tjera" fq.31

\subsubsection{Ambivalenza}

Shpesh motivimi i personave që kërkojnë ndihmë për probleme të vartësisë duket i lëkundshëm dhe përshtypja që kanë operatorët është që pacienti alternon me shpejtësi momente kur dëshiron ndryshimin me momente kur kundërvihet me energji. Pikërisht, për problemet e vartësisë alkolistët, tosikodipendentët, qëndrojnë të lidhur me sjelljen e tyre edhe pse i njohin rreziqet dhe dëmet që ajo sjell. Në raste të tilla, reagimi instiktiv i operatorit është të shtyjë subjektin drejt ndryshimit duke i përmedur dhe renditur seri argumentash në favor të ndryshimit. Teknikat e përdorura në intervistën e motivimit kanë si qëllim menaxhimin në mënyrë të dobishme të ambivalencës në këshillim (Miller, Rollnick, 1991, fq.55). Sipas autorëve, ambivalenza konsiderohet "normale, e pranueshme, e mirëkuptueshme" pasi i mundëson operatorit të shoh më qartë kompleksitetin e dilemës sesa "të sulmojë mostrën e mohimit". Ambivalenza interpretohet si sintom konflikti (në veçanti si konflikt i tipit tërheqje-shmangie) sesa të atribuar "një patologjie vartësie të caktuar" apo "mekanizmave mbrojtës të një çrregullimi karakteri (mohim, racionalizim, projektim)" (Miller, Rollnick, 1991, fq.63-64). Duke shmangur së atribuari vetëm fenomene "negative" pacientit si mohimi dhe mungesë motivimi, e detyron operatorin të ketë parasysh sjelljen e vetë dhe të zhvillojë në çdo kohë një sforcim për t'u vendosur në vendin e klientit-pacient me emocionet dhe ndjenjat e atij që kërkon ndihmë. Për të përmbushur analizën e konfliktit është e rëndësishme që operatori të shmangi caktimin e vlerave faktorëve që përfshijnë ndryshimin, pasi vlerësimi i kostos dhe benefiteve është tepër subjektive dhe zor se vlerat e operatorit mund të perputhen me ato të klientit. Ajo që për disa është shumë e rëndësishme si (puna, familja, shëndeti) për dikë tjetër ka pak apo aspak rëndësi. Gjithashtu, duhet patur parasysh se dëshirueshmëria ndaj sjelljeve "të rrezikshme", rriten nëse ato bëhen strumenta për afirmimin e lirisë personale që duket e cënuar. Në shumë raste, pranimi se familjarët kanë të drejtë për sa i përket teprisë së konsumimit të një substance, do të thotë të pranohet dështimi në menaxhimin e autonomisë personale dhe nevoja për ta kufizuar atë. Qasja motivacionale përkundrazi, kërkon të ruajë vetëbesimin e subjektit duke u bazuar në teorinë e vetë-efikasitetit të Bandurës, sipas së cilit, operatori e lë pacientin të thotë gjithmon fjalën e fundit.

\subsubsection{Aspektet Metodologjike}

Konceptet bazë të intervistës së motivimit janë:

1. ambivalenza nuk është fenomen patologjik

2. motivimi nuk është statik

3. ekzistojnë faza të ndryshme të proçesit të ndryshimit, nëpërmjet të cilave duhet modeluar ndërhyrja

4. sjelljet dhe qëndrimet e operatorit nuk duhet të ndikojnë në shfaqjen dhe kristalizimin e fenomenit të rezistencës përgjatë këshillimit

Teknikat e intervistës së motivimit bazohen në pesë parime themelore:

1. të shprehurit empati

2. zhvillimi i frakturës së brënshme

3. shmangie të debateve

4. përdorimi dhe menaxhimi i rezistencave të pacientit

5. mbështetja e ndjenjës së vetë-efikasitetit

Për të zbatuar në praktik parimet e lartpërmendura, operatori mund të përdori në fushën e counselling të motivimit teknika si:

1. formulimi i pyetjeve të hapura

2. praktikimi i dëgjimit refleksiv

3. të mbështesi dhe të konfirmojë

4. të përmbledhi

5. të nxit deklaratat automotivuese

6. të ristrukturojë 5

\subsection{Konteksti komunikues}

Për sa i përket kontekstit komunikues spitalor duhet patur parasysh marrëdhënia me personin që jeton në kufizim të lirisë 
së tij dhe i nënshtrohet kushteve që kanë të bëjnë me çfarë dhe kur të hajë, çfarë veshje të ketë, kur të flejë, çfarë ilaçe të pijë, kur të dali nga dhoma apo me kë ta ndajë etj. Për sa i përket ambjentit komunikues (Berceli, et al., 1999) nënvizon si komunikimi rezulton e influencuar nga faktorë të jashtëm dhe aspekte që i paraprijnë siç janë:

- $\quad$ ku jemi

- me kë jemi

- sa veta jemi

- c çfarë raportesh kemi me të tjerët

- motivi i takimit

- $\quad$ siguria e vetes

- $\quad$ besimi ne vetvete

- personaliteti

Flitet për "setting apo kontekst të brenshëm" kur i referohemi qëndrimit të brenshëm të operatorit, që ka të bëjë me "disponueshmërinë", "të qenurit i hapur" me pacientin në atë moment në atë vend.

\subsubsection{Komunikimi i diagnozës}

Komunikimi i diagnozës respekton rregullat e komunikimit të një lajmi të keq. Një lajm i keq është një informacion që modifikon në mënyrë drastike dhe negative vizionin e personit me infeksionin Hiv/Aids apo sëmundje tumorale. Detyra e profesionistit konsiston ta bëjë më pak traumatike kalimin nga perceptimi i realitetit të pacientit (realiteti subjektiv) me gjendjen reale (realiteti objektiv). Janë pesë motivet që argumentojnë nevojën për të komunikuar lajme të këqija (De Santi et al., 2007; Baile et al., 2000):

1. Është e drejtë e pacientit - njohja e diagnozës dhe prognozës përfaqësojnë kushtet e nevojshme për të qënë të ndërgjegjshëm në pjesmarrjen dhe vendimarrjen e kurimit.

2. Përfaqëson një nga detyrat e profesionistit - si ata që punojnë në spital, dhe mjekët e familjes.

3. Është detyrim për operatorët e shëndetit - në veçanti të mjekut për t'i komunikuar pacientit diagnozën të përcaktuar nga motivacione juridike, deontologjike dhe etike.

4. Lehtëson proçesin e përshtatjes ndaj sëmundjes - literatura përmend shumë studime që evidentojnë efektet positive të një komunikimi korrekt ndaj personave me Hiv/Aids për sa i përket kuptimit të informacionit. (Maynard, 1996; Buton et al., 1995; Ford et al., 1996).

5. Përmirëson cilësinë/sasinë e të dhënave të grumbulluara në anamnez.

\subsubsection{Si të Komunikojmë Lajme të Keqija}

Në modelet për të komunikuar lajme të këqija, të përdorura në fushën e onkologjisë janë:

- Modeli i mos-komunikimit: më i përhapur kryesisht në vendet mesdhetare me kulturë latine.

- Modeli i komunikimit të plotë: tipike në vendet anglosaksone si USA, Kanada, Australi dhe Europa veriore.

- Modeli i komunikimit të personalizuar: sugjerohet si më i preferuari, ku sintetizon protokolle të ndryshme të njohura rishtazi në literaturë si:

a. Udhëzimet e $\mathrm{OBSH}$ "Communicationg bad news" - dokument për të kuptuar aftësitë e kërkuara dhe realizimin e ndërhyrjeve në praktikat klinike. (WHO, 1993)

b. Protokolli i Girgis dhe Sanson-Fisher - dokument me udhëzime mbi komunikimin e lajmeve të keqija. (Girgis e Sanson-Fisher, 1998)

c. Protokolli i Okamura - dokument me udhëzime për t'i komunikuar pacientit të vërtetën të adoptuar në Japoni nga National Cancer Center dhe spitale të tjera. (Okamura et al., 1998)

d. Protokolli i Buckman i quajtur SPIKE - inicialet e 6 hapave kryesore që përbëjnë ndërhyrjen nga eksplorimi i njohurive dhe pritshmërive të pacientit deri në komunikimin e të vërtetës duke respektuar ritmin dhe vullnetin e pacientit. (Baile et al., 2000).

\subsubsection{Sugjerime mbi Komunikimet e Lajmeve të Keqija}

Sipas Tuberi (Tuberi, 2005) sugjeron:

- Flisni me gjuhë të thjeshtë dhe të qarte.

- Pyesni veten: "Çfarë do të thotë ky lajm për pacientin?" 
- Takohuni fillimisht në një "terren të qetë" (lereni pacientin t'ju rrëfeje historinë i tij dhe gjërat që ai njeh).

- Mos e jepni të gjithë lajmin, informacionin përnjëherësh: mund t'i ktheheni argumentit në takimet e tjera.

- Të jeni gati për të vëzhguar, për të marrë dhe t'ju përgjigjeni emocioneve të pacientit.

- I jepni kohë pacientit për të bërë pyetje, dhe bëni dhe ju pyetje.

- Shmangni ashpërsin, të qënurit i drejtpërdrejtë dhe mos shkatërroni të gjitha shpresat.

Antonio Alfano në vëllimin e tij Komunikimi shëndetësor në shërbimet shëndetësore dhe sociale (Alfano, 2001) identifikon 10 rregulla të thjeshta për të përmirësur komunikimin me pacientët:

1. Mos shprehni kurrë shumë koncepte njëkohësisht.

2. Kur flisni drejtohuni gjithmon direkt pacientit, duke shmangur së bëri gjeste që mund ta shpërqëndrojnë.

3. Kur duhen trasmetuar informacione të rëndësishme, nëse pacienti e dëshiron, kërkoni t2 përfshini edhe familjarët e tij nëse janë të pranishëm.

4. Përsërisni nëse nevojitet informacionin disa herë në mënyrë që të jetë $i$ kuptueshëm, sidomos nëse personi që dëgjon ka një nivel të ulët formimi.

5. Planifikoni diskutimin në mënyrë të tillë që pikat më kryesore të informacionit të jepen si në fillim dhe në fund të takimit.

6. Për të qënë më të qartë, përdorni shembuj që kuptohen më lehtë për pacientin, ndoshta duke ju referuar ngjarjeve klinike të pacientit apo familjarëve të tij.

7. Që pacienti të ndihet më rehat dhe ta ketë më të lehtë kuptimin e informacionit, përdorni terminologji të gjuhës së folur, popullore, ndonjëherë dhe dialekte.

8. Kur jepen udhëzime mbi dozat dhe llojin e medikamenteve që pacienti duhet të perdorë, i ilustroni me shembuj praktik: (qartësoni mbi llojin e ilaçit kapsul, tableta, ngjyra, forma, si mund të ndahen; në përdorimin e shurupit përcaktohet doza e marrë me lugë gjelle apo lugë e vogël).

9. Sigurohuni që pacienti ka kuptuar, duke e përfshirë në diskutim dhe i kërkoni të përsërisë dozimin e medikamenteve që duhet të marri.

10. Shprehni gjithmon optimizëm, duke inkurajuar pacientin në vështirësi: teprim pesimizmi mund ta çojë në një pozicion skepticizmi, me rënie të mundshme të besimit dhe refuzim të kurës dhe terapis.

\subsection{Formimi dhe Trajnimi}

Nevoja per trajnime specifike për një përgatitje të duhur psikologjike të operatorëve është gjerësisht e njohur. Mungesa e përgatitjes së nevojshme të tyre, mund të nxis reagime mbrojtëse të afta për të ndikuar negativisht marrëdhënien me pacientin dhe ambjentin e punës. Efektet që formimi sjell në qëndrimet në punë konsistojnë në perceptimin pozitiv të profesionit, në favorizimin e njohjes të aftësive të veta për të vendosur një gjendje kontrolli mbi disa faktore të stresit. Trajnimet duhen të përfshijnë zona të vështira në të cilat është e pranishme komponenti emocional: vuaitja, dhimbja, vdekja, zija në mënyrë që të theksojnë njohurit dhe aftesit për të menaxhuar komunikimin. Përmirësimi i këtyre aspekteve prodhon një rikthim pozitiv të menjëhershëm mbi raportin me pacientin dhe redukton rrezikun e frustrimit dhe burnout për operatorin e shëndetësisë. Mbështetja ndaj operatorëve të fushës së shëndetësis duhet të vendoset përtej dhe jo vetëm përmes trajnimeve teknike shkencore, por edhe përmes përgatitjes mbi përbërësit që përfshijnë marrëdhënien, komunikimin, dëgjimin dhe këshillimin. Aspekt tjeter i rëndësishem ka të bëjë me trajnimin për zhvillimin e aftësive për të punuar në ekip, përmes eksperiencave përfshirëse në aktivitete në grupe, të finalizuara për përballjen e vështirësive të lidhura me situata konfliktuale individuale (shembull grupet e vetë-ndihmës) dhe të marrëdhënieve midis komponentëve të grupit dhe ekipeve të ndryshme që veprojnë brënda të njëjtës strukturë. Në planin e mbështetjes, duhet të parashikohet dhe mundesia që operatorët të përfitojnë nga drejtimi individual i personalizuar, i kryer nga një figurë profesionale me kompetenza specifike psh, një psikolog dhe/apo psikiatër. Trajnimi për aplikimin e intervistës së motivimit ka mundësi për të qënë më efikase nëse zgjatet në kohë, me aktivitete verifikuese, mbikqyrje dhe coaching.

\subsubsection{Strategji Komunikimi Efikas}

1. Pyetje të hapura: Shembuj: "Më thoni diçka më shume rreth dhimbjeve tuaja" "Për çfarë informacionesh keni më tepër nevojë të dini?"; "Mund të më jepni një shembull?"

2. Inkurajime minimale:"Humm"; Ah-ah; "Po"; "Dhe?" pohoni me kokë apo anohuni drejt bashkëbiseduesit.

3. Parafrazim dhe përsëritje:"Ju po më thoni se u shqetësuat shume kur ju propozua përdorimi i morfines kundër dhimbjeve"; "Kam përshtypjen se ju jeni shqetësuar pasi ndiheni barr për familjaret tuaj...është kështu?" 
4. Sigurohuni që tjetri ka kuptuar saktë: "Çfarë do t'i tregoni familjarëve tuaj mbi sa thamë?"; "A mund të më përsërisni me fjalët tuaja ato çfarë ju thash pasi dua të jem i sigurt nëse jam shpjeguar qartë".

5. Kundërshtoni me takt dhe indirekt: "Ju më thatë se keni një raport besimi reciprok me fëmijët tuaj, por nuk u keni komunikuar semundjen tuaj. Mendoni se kjo mund të ndikojë në marrëdhëniet tuaja?"

6. Përmbledhja: "Më lejoni të përmbledh diskutimin tuaj dhe nëse e kam kuptuar mirë....."

\section{Përfundimet}

Intervista e motivimit është një tipologji këshillimi që e ka zanafillën nga counselling i marrëdhënieve. Fushat e aplikimit ku kjo metodë gjen jetë janë:

- $\quad$ fillimisht si ndërhyrje nga vartësitë si alkoli, drogat, 1985

- në promovimin e stileve për një jetë të shëndetshme

- duhanpirja

- në promovimin e screening

Intervista motivacionale synon përballjen, ndryshimin, autonominë. Ndryshimi ka tre karakteristika: 1) të qenurit gati; 2) të deklaruarit i disponueshëm; 3) të dish ta bësh.

Intervista motivuese është tipologji counselling që bazohet në aleancën terapeutike midis mjekut dhe pacientit, është e strukturuar në kohe, fillon me një analizë të pyetjes, është e aplikueshme jo vetem në kurim por edhe në fushën e parandalimit sekondar dhe terciar. Është e zbatueshme kur mungojnë motivimi dhe ndërgjegjshmëria rreth problemit. Intervista e motivimit është dialog empatik, bazohet në dëgjim dhe lejimi i personit që gjendet përballë nesh të flasë lirisht përbën rregullin e parë të kësaj metode. Është e rëndësishme respektimi dhe i kohës së klientit-pacient ashtu siç është e nevojshme përcaktimi i pikënisjes me marrjen dhe grumbullimin e informacionit por pa u nxituar, detajet rekuperohen në kohën në vijim. Duhet patur parasysh se objektivat e pacientit ndryshojnë nga ato të operatorit të shëndetit. Pacienti duhet siguruar se jeta e tij do të ndryshojë por jo vetëm negativisht, dhe kjo i komunikohet. Ndërtimi i aleancës para çdo Iloj ndërhyrje, trajtimi, përmes dëgjimit krijon besimin tek pacienti. Gjithashtu dhe operatori i shëndetësisë duhet të ketë besim në atë që bën dhe si e bën, dhe tek pacienti për të cilin duhet të kujdeset. Para çdo lloj veprimi eksplorohet pranimi i gjendjes aktuale dhe statusi i të semurit, statusi pacient. Një instrument që përdoret në intervistën motivacionale është ditari përmes së cilit arrihen dy vlerësime: 1) vlerësimi i sjelljeve jo përshtatese; 2) vlerësimi i impenjimit, resurseve personale dhe i rezultateve të arritura. Duhet të tregohemi të kujdesshëm ndaj aderences fallso, çdo operator duhet të punojë me pikat e forta të fshehura, të nënvlerësuara nga pacienti ku ky i fundit duhet mirekuptuar, pritur dhe mbështetur si person dhe jo për patologjinë që mbart. Kriteret e cilësis së komunikimit operator-pacient janë:

1. efikasiteti - bazuar në plotësimin e objektivave

2. të qenurit i duhur - individualiteti midis komunikuesve dhe kontekstit

3. përshtatshmëria - sasia e komunikimit e nevojshme, e thjeshtë dhe koerente

4. vlershmëria - matja e cilësis midis komunikimit verbal dhe komunikimit joverbal

5. fleksibiliteti - komunikim jo shumë i ngurtë, i vrazhdë, por as shumë miqësor

Tre pyetjet kyçe që i referohen çdo lloj komunikimi janë: Kush komunikon? Mbi çfarë komunikohet? Përse komunikohet? Aspektet e bashkëbiseduesit që duhen njohur janë:

- Gjinia

- Mosha

- Sa profesionista të tjerë ka takuar? (mjek, infermier, psikolog etj)

- Niveli i formimit arsimor, kulturor

- Qendrimet, sjellja

Zonat që duhen eksploruar:

- Ndjenjat

- Idete

- Pritshmëritë

- Konteksti

- Çfarë ndjen pacienti?

- Si ta interpretojmë çfarë po ndodh?

- Çfarë prisni të ndodhë?

- Çfarë ka ndryshuar prej kohës kur jeni sëmurur?

Ambjentet organizative të përfshira në counseling dhe intervistën motivuese janë dy: 
1) setting i brenshëm (duhet të jetë i mbrojtur, sigurues, duhet të heshtim çdo lloj zhurme për të dëgjuar problemet e tjetrit, distanca nga pacienti parashikohet $50 \mathrm{~cm}$ )

2) setting i jashtëm (përcaktohet kultura, vlerat personale, gjendja emocionale)

Aleatët dhe armiqtë e komunikimit janë: mekanizmat mbrojtës, barrierat komunikuese, kanalet pamore, dëgjimore, kinestetike të komunikimit (gjuha përçohet përmes 5 kanaleve sensoriale që mbledhin informacionin nga realiteti). Çdo individ ka kanalin ndjesor të tij të privilegjuar dhe duhet kerkuar përshtatja me kanalin sensorial të tij të zgjedhur. Faktori kohë është deçiziv për një komunikim sa më të mirë. T’i japësh kohë pacientit mundëson ndërtimin e një marrëdhënie të mirë terapeutike, duke marrë më shumë informacione klinike mbi sëmundjen. Foljet që duhen përdorur gjatë intervistimit, këshillimit janë: dëgjoj, krahasoj, qartësoj, fokalizoj, inkurajoj, perifrazoj, pasqyroj, përmbledh. Foljet që duhen shmangur janë: refuzoj, kundërshtoj, përkrah, imponoj opinionet e mia. Disa prej rekomandimeve mbi komunikimin mjek-pacient janë:

- Pacienti a më kupton?

- E pyes nëse më ka kuptuar drejt

- Mos dhënia e informacionit, lajmit përnjëherësh

- Jepni kohë pyetjeve

- Mbani një komunikim të thjeshtë

- Bëni pyetje sqaruese

- Të dish të vëshgosh dhe të mbartësh detaje informacioni

- Të përgjigjesh emocioneve të pacientit.

Treguesit e cilësisë së counselling: vendi (studio); pozicioni (të ulur pranë); kohëzgjatja (10min); gjuha (e thjeshtë dhe e kuptueshme).

Disa nga rregullat e përgjithshme të një edukate të mirë në komunikimin me pacientët dhe familjarët e tyre parashikojnë kritere si:

- prezantimi emër, mbiemër, kualifikimi i mjekut kurues

- $\quad$ i drejtohemi me ju

- shmanget të folurit në grup në prani të pacientit

- $\quad$ mbahet mend emri i pacientit

- pacientët thirren me emrin që dëshirojnë

- $\quad$ shmangni të flisni me pacientin në këmbë

- mbani kontakt pamor të vazhdueshëm

- mos përdorni fjalë të vështira, pak të kuptueshme

Këto rregulla të një edukate të mirë, shpesh të papërmendura, të ditura, luajnë një rol të rëndësishëm në ndërtimin e aleancës terapeutike dhe aderences ndaj kurimit. Aplikohen jo vetëm me pacientë të sëmurë me Hiv/Aids apo sëmundje terminale, por me çdo pacient në çdo lloj konteksti shëndëtësor. Shpesh keto rregulla pengohen nga kohë e kufizuar institucionale, kultur komunikuese prevalente midis mjekëve. Qëllimi i tyre është se pacientët dhe familjarët e tyre duhen trajtuar me respekt dhe edukatë.

\section{Referencat}

Guefi, G. P "Le basi teoriche del colloquio motivazionale" pdf

Guefi, G. P "Il colloquio motivazionale per alcolisti e tossicodipendenti" pdf

Mauri, B "Il counseling motivazionale - modulo 3 alcologia territoriale pdf

Linee guida cliniche per la l'identificazione e l'intervento breve "L'alcol e l'assistenza sanitaria primaria" (2010) Istituto Superiore di Sanità, Osservazione Nazionale Alcol. A cura di: Scafato, E., Gandin, C., Patissi, V.

Rapporti ISTISAM 08/43 "Manuale di autovalutazione della comunicazione in ambito sanitario Hiv/Aids. A cura di De Santi, A., Morosini, P. Teodori, M

Giornata formativa sul colloquio motivazionale - ASPIC Roma (2010) 